\title{
BARCELONA ANTE LA MIRADA HABERMASIANA. PRIMEROS MATERIALES PARA UNA SOCIOLOGÍA DE LA ACCIÓN COMUNICATIVA
}

\author{
Barcelona under the Habermas Perspective. First Steps towards a Sociology of \\ Communicative Action \\ Genís Plana Joya \\ Universitat Autònoma de Barcelona \\ iz.geplan@gmail.com
}

\section{Resumen:}

Este texto presenta una investigación de la interacción social en el espacio público de Plaça del Sol (Barcelona) realizada desde el marco conceptual que ofrece el pensamiento de Jürgen Habermas al respecto de la «opinión pública» y la «racionalidad comunicativa». Después de dar cuenta de los aspectos metodológicos y teóricos que guiaron el estudio, el artículo se centra en mostrar los resultados obtenidos en consonancia con la «acción comunicativa» planteada por el filósofo frankfurtiano. Por último, la actividad humana que se reproduce en la esfera pública estudiada supone el fermento a partir del cual plantear una discusión al respecto del ideal de ciudadanía cívica y políticamente activa defendido por Jürgen Habermas y Hannah Arendt.

Palabras clave:

Acción comunicativa, Habermas, opinión pública, ciudadanía, espacio público.

\begin{abstract}
:
This text presents an investigation of social interaction taking place in the public space of Plaça del Sol (Barcelona), conducted in terms of the conceptual framework offered by the thought of Jürgen Habermas regarding "public opinion" and "communicative rationality". After giving an account of the theoretical and methodological aspects which have informed the study, the article focuses on presenting the findings in concordance with the Frankfurtian philosopher's conception of 'communicative action'. Lastly, the studied human activity of the public sphere constitutes a foundation from which a discussion of ideal of a civic and politically active citizenship defended by Jürgen Harbermas and Hannah Arendt.
\end{abstract}

\section{Keywords:}

Communicative action, Habermas, Public Opinion, Citizenship, Public Space. 
Barcelona ante la mirada habermasiana. Primeros materiales para una sociología de la acción comunicativa

Recibido: 05/12/2018

Aceptado: 25/06/2019

\section{INTRODUCCIÓN}

Aunque sean diversas las limitaciones que las páginas que conforman el presente artículo se le puedan atribuir, ninguna corresponderá a la ausencia de intrepidez. Pues únicamente desde una posición audaz será posible esbozar los primeros materiales por medio de los cuales situar una posible base empírica a las líneas maestras de la teoría de la acción comunicativa de Jürgen Habermas.

En palabras del filósofo alemán, "la teoría de la acción comunicativa establece una relación interna entre praxis y racionalidad", para lo cual "investiga las suposiciones de racionalidad inherentes a la práctica comunicativa cotidiana" (Habermas, 1993: 100). Dicho esto, será preciso indicar desde este mismo momento que el presente escrito asume el objetivo de mostrar los resultados de una investigación al respecto de las formas de interacción social en el espacio público relativo a la Plaça del Sol de la Vila de Gràcia (Barcelona) desde las coordenadas conceptuales que nos ofrece la obra del que probablemente sea el más reputado de los representantes contemporáneos de la Escuela de Frankfurt.

Así pues, no se pretende ofrecer una doxología al respecto de la Teoría Crítica habermasiana, sino plantear la posible materialización práctica de sus postulados normativos. La razón de ser de semejante intención exige advertir, así como afirma Antoni Domènech (1981: 32), que el fundamento de la Teoría Crítica no es arbitrario, sino inherente a la estructura de la acción social. Apartándose del trascendentalismo de una «pragmática universal» que teoriza al respecto de una situación ideal de diálogo, la "pragmática empírica» sobre la que se asienta este estudio debe entenderse como la investigación de los fenómenos de comunicación a partir del análisis sociológico de la relación interpersonal, de manera que los actos comunicativos queden contextualizados dentro del marco relativo a la interacción efectuada en la situación social que se sitúa en Plaça del Sol. Pero antes de avanzar, lo que supondrá sintetizar las pautas de acción e interacción presenciadas, resulta perentorio describir cuál es la situación que nos encontramos en Plaça del Sol.

PLAÇA DEL SOL, VILA DE GRÀCIA (BARCELONA)

$\mathrm{Si}$, de ser el caso que desconociésemos los rasgos que le confieren sentido a la interacción social que se desarrolla en la plaza, se nos afirmase que prácticamente todas las tardes -pero en especial los fines de semana- se produce en Sol una sentada de personas jóvenes, probablemente pensásemos que, de manera análoga a las ocupaciones cívicas del $15 \mathrm{M}$, nos encontramos ante una movilización social expresada por cauces no convencionales. No obstante, no existe homología posible entre la congregación humana de Plaça del Sol y las protestas acaecidas durante mayo de 2011 en las principales ciudades españolas. Así que debemos comprender 
este fenómeno social que en el espacio público de la plaza tiene lugar desde parámetros conceptuales completamente dispares.

A partir de una primera descripción del fenómeno ya podríamos observar que, a medida que avanza la tarde, decenas de jóvenes -llegando a ser cientos durante los días de tiempo atmosférico favorable- se congregan en la plaza en pequeñas camarillas, sentándose en el suelo en forma de corrillos o grupos, para conversar sosegadamente mientras, la mayor parte de las veces, acompañan el diálogo con la ingesta de bebida. Plaça del Sol acontece así un ámbito público que de manera continua se recrea mediante la acción concertada de los individuos que ahí confluyen, los cuales se reúnen e intercambian palabras y experiencias, al tiempo que, podría suponerse, semejante interrelación potenciaría sus respectivas capacidades de juicio $y$, en consecuencia, desarrollaría su sensibilidad social y compromiso político. Aunque sea con prudencia y mesura, un somera observación de las pautas de acción e interacción social en la plaza nos lleva a sospechar que nos encontramos ante el ideal de esfera pública pergeñado por aquellos autores cuyo modelo normativo de comunidad política requiere como condición de posibilidad la coordinación de la ciudadanía en espacios deliberativos de toma de decisiones.

A la manera en que Hannah Arendt ambiciona la esfera pública, Plaça del Sol materializaría el espacio en que, por medio de la interacción persuasiva que supone la deliberación colectiva, los ciudadanos interactúan y deciden al respecto de asuntos de interés común (Passerin d'Entrèves, 2012: 186). En pocas palabras, Plaça del Sol daría muestras de reproducir, bajo modulaciones contemporáneas, los ecos del ágora ateniense, lugar donde un mismo asunto puede ser presentado desde múltiples perspectivas: ya sea desde los puntos de vista relativos a cada una de las personas integrantes de un grupo, ya sea desde cada uno de los grupos o corrillos que de manera espontanea se congregan en la plaza y de forma aleatoria se distribuyen sobre su superficie.

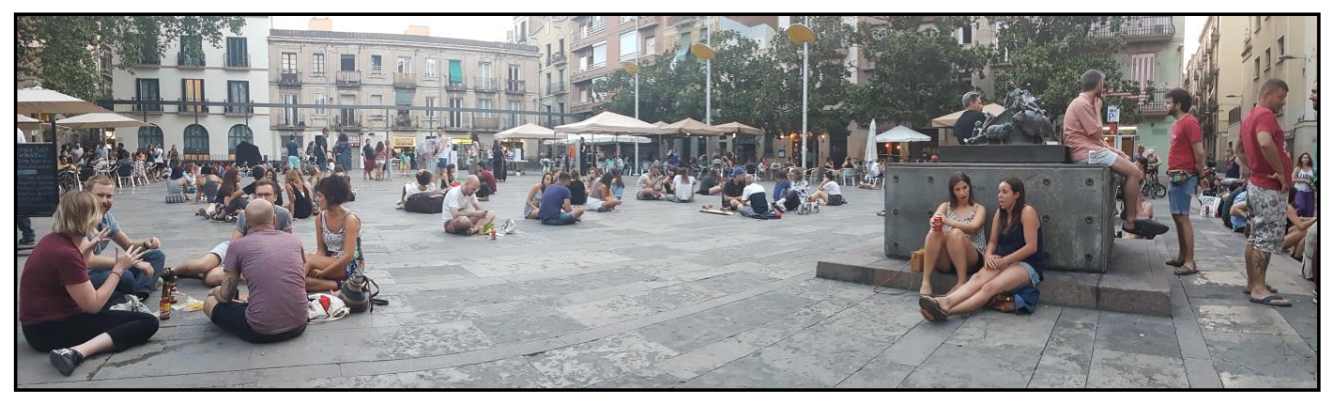

Panorámica de Plaça del Sol

En definitiva, la potencialidad política de Plaça del Sol se pondría de manifiesto desde el momento en que se concibe el espacio público de la plaza como ese lugar "donde los ciudadanos pueden encontrarse, intercambiar sus opiniones y debatir sus diferencias y buscar alguna solución colectiva a sus problemas" (Passerin d'Entrèves, 2012: 194). Por lo que, de ser el caso que esbozásemos una hipótesis plausible al 
respecto del fenómeno descrito dentro de la lógica de la acción comunicativa, nos sentiríamos tentados a sostener que nos encontramos ante un espacio público donde se desarrolla una dinámica y continuada interacción social que pareciera ser óptima para intercambiar opiniones $y$, por consiguiente, dirimir las diferencias mediante discursos confrontados dentro de pautas democráticas. Ciertamente, la comunidad de sujetos presentes en Plaça del Sol pareciera garantizar el derecho de cada cual a dar su opinión, lo cual es fundamental para la floración de una cultura política vibrante.

No es de extrañar, por tanto, que pudiéramos concebir la plaza como el espacio adecuado para que el juicio pudiese encontrar mayores recursos para poder ser válido, lo que, en última instancia, pareciera proporcionar cobertura fáctica a la racionalidad comunicativa teorizada por Jürgen Habermas. Teniendo esto en consideración, su teoría de la acción comunicativa ha sido la fuente de inspiración que ha motivado la pesquisa realizada. Pero antes de apresurarnos a mostrar sus resultados, será conveniente desplegar una propedéutica inicial del pensamiento habermasiano a fin de encuadrar dentro de sus contornos la situación social que se expresa en la plaza.

\section{MARCO TEÓRICO: MODERNIDAD Y OPINIÓN PÚBLICA}

Comprender los vínculos entre Plaça del Sol y el ideal normativo que subyace en el concepto de racionalidad comunicativa exige considerar, primero de todo, que «la palabra» es la superficie de inscripción de la mayor parte de la interacción social que se realiza en la plaza ${ }^{1}$. Consiguientemente, la acción no podría sostenerse en ausencia del componente cívico y dialogante de los sujetos, quienes reproducen una gramática de la conducta donde los valores ético-políticos fundados en la libertad y la igualdad son constitutivos de la comunidad. Surgidos al calor de la modernidad, estos valores serían condición necesaria para que el de Plaça del Sol sea un logos exento de coacción sin el cual la razón no podría circular por medio de la comunicación.

Así pues, un escenario como el referido nos sitúa ante la defensa habermasiana de la modernidad. En su libro El discurso filosófico de la modernidad, Habermas sostiene que la modernidad, a diferencia de cómo era concebida por Adorno y Horkheimer, no sería el resultado necesario de la instrumentalización de la sociedad. De modo que, aunque pareciera ser que "en la cultura moderna la razón queda definitivamente despojada de su pretensión de validez y asimilada al puro poder" (1993: 142), para Habermas no resultaba forzoso que la razón, en lugar de emancipar a la humanidad, la sometiera a una lógica instrumental. Por decirlo a la manera de Garcés (2015: 217), "según el análisis habermasiano, la relación entre

\footnotetext{
${ }^{1} \mathrm{Al}$ ser preguntados por las acciones específicas que se desarrollan en la plaza, la amplia mayoría de actuantes ha indicado "conversar" o, en su defecto, vocablos análogos como "hablar", "parlotear", etc. Dejando de lado que la otra acción asumida es la de "beber" acción que, siempre y cuando no se realice de manera desmesurada, no compromete la concordia existente entre los presentes-, la actividad humana en la plaza no proporciona ninguna otra acción que comporte la unión de cuerpos diversos: ninguna de las respuestas correspondió a acciones como bailar, pelear, discutir o jugar.
} 
racionalización y deshumanización no responde a una lógica interna de la propia razón, sino a una relación externa entre los modos de integración social y sus correspondientes formas de racionalidad". Precisamente fue la colonización del lebenswelt -esto es, el «mundo de la vida»- por parte de la «racionalidad instrumental» del «sistema» ${ }^{2}$, lo que comportó que la modernidad ocultase los procesos de emancipación humana sintetizados en la aspiración, inequívocamente moderna, de alcanzar la libertad y la igualdad.

De modo que, en tanto en cuanto en Plaça del Sol parecieran concretarse las divisas emancipadoras de la modernidad, cabe pensar que los comportamientos que ahí se llevan a cabo no responden, o al menos así lo entendería Habermas, a «acciones rituales» propias de lo que denomina como «el mundo de la vida» de las «sociedades arcaicas». Bien por el contrario, nos encontraríamos ante funciones socialmente integradas y absorbidas por el potencial racionalizador de la acción comunicativa. Pero este tránsito hacia la acción comunicativa no es posible sin que, previamente, "la autoridad de lo santo [quedase] gradualmente sustituida por la autoridad del consenso" (Habermas, 1999b: 112). Aunque fueran cruciales las revoluciones contra los monarcas absolutos que dieron lugar al mundo moderno (la legitimidad del poder dejó de proceder del derecho divino para recaer sobre la voluntad colectiva), ya encontramos en el famoso pasaje del mito al logos que se dio en la Atenas clásica las condiciones de posibilidad para que el órgano legislativo estuviese en manos de una asamblea participada por la ciudadanía (isegoria y parresia). En este sentido es que Plaça del Sol pareciera que "retoma el espíritu de la ciudadanía clásica (...) caracterizada por el interés y el compromiso con lo público, por la discusión con los conciudadanos sobre los asuntos comunes y la vigilancia respecto al poder" (Peña, 2000: 35).

No obstante, si bien es cierto, como se acaba de apuntar, que la participación de la ciudadanía en los asuntos públicos no es un fenómeno exclusivo de la modernidad, pues ya los ciudadanos libres (koyné) conversaban al respecto del gobierno de la polis en el espacio del ágora ${ }^{3}$, la organización del espacio social de la «opinión pública», por el contrario, sí sería una faceta distintiva de la modernidad. A ella le dedica Habermas su Historia y crítica de la opinión pública, un libro donde explica el surgimiento de la opinión pública (Öffentlichkeit) a partir de la vigorización de la sociedad civil, principalmente británica y francesa, conformada por el asociacionismo de la «alta sociedad» dieciochesca y decimonónica.

\footnotetext{
${ }^{2}$ Dicho de manera esquemática, "el «mundo del sistema» integra todo aquello regido por reglas neutras y perteneciente al reino de lo técnico-organizativo, mientras que el «mundo de la vida» integra el tejido mudable de lo intersubjetivo, opinable e intencional" (Rodríguez Ibáñez, 2011: 670). Sin embargo, sería inadecuado pensar que los mecanismos económicos y administrativos del «sistema» y las lógicas socialmente aceptadas del «mundo de la vida» se encuentran en esferas aisladas. Entre ambas mediaría una institucionalidad sin la cual sería inconcebible pensar la sociedad civil (Arato y Cohen, 1999).

${ }^{3}$ Por consiguiente, "el término «moderno» apareció y reapareció en Europa exactamente en aquellos períodos en los que se formó la conciencia de una nueva época a través de una relación renovada con los antiguos y, además, siempre que la antigüedad se consideraba como un modelo a recuperar a través de alguna clase de imitación" (Habermas, 2008: 20).
} 
La «opinión pública», constituida en sus fases iniciales como «publicidad burguesa», surgía como un espacio situado entre el ámbito de lo privado, relativo a la familia y al patrimonio, y la esfera de lo público, vinculada a las instituciones de gobierno. Es desde el raciocinio que se instituyen unas reglas de discusión por las cuales los hombres instruidos de la época conversan de asuntos públicos en «salones» y «casas de café». Por consiguiente, antes que la "opinión pública» asumiese, ya en el siglo $\mathrm{XX}$, funciones de reclamo publicitario o propaganda comercial (Werbung), ésta se caracteriza como el proceso por medio del cual "las gentes cultivadas procedentes de la sociedad aristocrática" y "la intelectualidad burguesa" (Habermas, 1981: 70) logra confrontar sus diferentes puntos de vista con respecto a las instancias del poder institucional. Así que la «opinión pública» tiene su germen dentro de élites específicas que no encuentran su equivalencia en la complejidad de la estructura socioeconómica de las sociedades contemporáneas.

Por lo que, una vez dicho lo anterior, será pertinente regresar a Plaça del Sol a fin de indicar que la labor de demarcar con amplia precisión la extracción social de los actuantes en la plaza resulta un ejercicio considerablemente problemático. En cualquier caso, parecieran darse las condiciones para afirmar que la composición social de los presentes en la plaza expresa cierto grado de holgura o comodidad económica ${ }^{4}$; pero ello no necesariamente debe verse como una continuación de la sociedad civil que emergió como parte de la esfera pública que analiza Habermas en la obra que acabamos de referenciar. A este respecto debe decirse que la "café society» británica, o el "dandismo» de los salones parisinos del siglo XIX, al estar orientados a la discusión de aspectos sociales, políticos o literarios, contaban con un componente intelectual que resulta ausente en -O, cuando menos, no característico de- la «jet set» $\operatorname{cosmopolita}^{5}$ que se reúne en Sol.

Habida cuenta de lo dicho, antes de avanzar hacia la explicación de la actividad social de Plaça del Sol desde la lógica de la acción comunicativa, conviene detenerse un momento a fin de aclarar el sentido de los resultados que nos encontraremos. Por lo que, aunque sea ésta una cuestión que iremos desentrañando en los siguientes apartados, desde este mismo instante será adecuado señalar que aquello que se percibe en Sol -una vez realizada la investigación- se asemeja al resultado de la paulatina retirada de los asuntos públicos por parte de una ciudadanía desprovista del espíritu crítico que en sus primeros compases

\footnotetext{
${ }^{4}$ No podemos inferir que la posición de los participantes sea acomodada por el mero hecho de disponer del tiempo recreacional asignado a su presencia en la plaza. De ahí que debamos respaldar esa conjetura mediante otro tipo de consideraciones: por ejemplo, alrededor de dos tercios de los entrevistados en edad adulta afirman ser sustentados económicamente por medio de rentas familiares.

${ }^{5}$ La alusión al cosmopolitismo viene dada por la significativa cantidad de participantes extranjeros, mayormente de países europeos, que se encuentran en Barcelona de manera temporal.
} 
caracterizaba la «opinión pública» ${ }^{6}$. Al fin y al cabo, como veremos posteriormente, podríamos pensar la plaza como una «esfera pública» significativamente corrompida por procesos mercantiles que deterioran la genuina participación pública.

Así pues, aunque no nos anticipemos por extenso las conclusiones a las que posteriormente nos referiremos, por ahora nos limitaremos a decir que la «opinión pública» que se descubre en la pesquisa sobre Plaça del Sol se encuentra alejada de la función crítica de la comunicación pública que caracterizó la sociedad civil en su etapa original. Si esto es correcto, entonces podemos encontrar en el ámbito social estudiado la concreción de los planteamientos de Habermas al respecto de la deriva de la opinión pública hacia un ámbito «manipulado» por la lógica del «sistema» y, por ello, subsumido a las "public relations» de la «sociedad de masas». Pero para entender cabalmente esta transformación de la «opinión pública», desde sus formas originales hacia las contemporáneas, a partir del estudio de caso planteado será conveniente atender a los procesos metodológicos desde los cuales ha sido abordada la situación social de la plaza.

\section{PROCEDIMIENTO DE INVESTIGACIÓN}

Al tratarse de un estudio cuyo propósito es desarrollar teoría a partir de los resultados obtenidos, nos encontramos ante una investigación básica cuyo alcance pretende ser descriptivo. Atendiendo a la dimensión temporal, este ha sido un estudio transversal en tanto que no ha sido necesario realizar un seguimiento de la muestra de la población analizada durante el periodo de cinco semanas en que se ha efectuado la investigación. A fin de dotarla de plena credibilidad, se ha realizado una observación persistente y una participación prolongada del fenómeno a estudiar. Así es que la investigación se ha efectuado por medio de una triangulación metodológica por la cual a una primera fase de observación no participante le ha seguido un periodo posterior de observación participante en que se han llevado a cabo diversas entrevistas personales.

La población a estudiar ha correspondido a todos aquellos sujetos que se encuentran en Plaça del Sol realizando con cierta continuidad alguna actividad. Puesto que sería inviable disponer de un registro exhaustivo de los individuos que componen la población de referencia, en tanto que ésta está conformada por individuos variables que, no obstante, participan de una misma dinámica social, el proceso de selección de las unidades muestrales necesarias para las entrevistas ha sido efectuado de manera no probabilística. De esto no debe desprenderse que los individuos hayan sido seleccionados de forma aleatoria, pues la selección de los sujetos que han compuesto el marco muestral se ha realizado en consideración con su aptitud para proporcionar información relevante al estudio. Por este motivo es que se ha optado por un muestreo intencional por medio del cual los individuos han sido seleccionados según representaban características usuales del conjunto de la

\footnotetext{
${ }^{6}$ Recordemos que, según Habermas (1981: 88), la «opinión pública» se caracterizaba por ser un "proceso en el cual el público compuesto por personas privadas raciocinantes se apropia de la publicidad reglamentada desde arriba, convirtiéndola en una esfera de crítica del poder público".
} 
población. Después de realizar doce entrevistas se ha alcanzando la saturación informativa según la cual se estima que la ampliación de la muestra ya no aportaría información relevante.

Aunque ha sido ya previamente apuntado, resulta importante recalcar que, después de emplear la observación como técnica de obtención de información, se ha realizado un mayor acopio de datos mediante entrevistas semiestructuradas que le han otorgado al entrevistador -autor del presente trabajo- la libertad necesaria para modificar improvisadamente los contenidos que preguntar. No resulta insólito afirmar que la entrevista ha sido la técnica de investigación por la cual han podido ser revelados aquellos aspectos de los sujetos que, subyaciendo bajo su comportamiento, no eran explícitos por medio de una práctica observacional. Sin duda, una información necesaria a la hora de valorar el grado en que los planteamientos habermasianos se adecúan a la dinámica social dentro de la cual los agentes llevan a cabo el acto comunicativo.

Por último, ya sólo considero ineludible señalar que se trata de una investigación acoplada al paradigma propio de la Teoría crítica, según el cual, aunque la realidad examinada sea cognitivamente aprehensible, en ningún caso ésta es inmóvil y, por consiguiente, definitiva. Nos disponemos a realizar, en oposición al empirismo abstracto del positivismo, una sociología directa y artesanal de la situación social. Para lo cual nos apoyamos en la denominada sociología interaccionista que, en oposición a las corrientes estructuralistas o funcionalistas, se presume óptima al momento de aislar una determinada acción social como unidad de estudio sobre la cual enfatizar el significado de los símbolos movilizados.

\section{ACCIÓN COMUNICATIVA EN PLAÇA DEL SOL}

A primera vista encontraríamos en la actividad social de Plaça del Sol un espacio exento de conflictos, relaciones de poder y antagonismos; la plaza sería así el escenario donde poder recrear una comunidad reconciliada consigo misma, basada en el diálogo y la convivencia. Plaça del Sol acontecería, al menos aparentemente, la esfera pública en la que se congrega una ciudadanía cuya actitud cívica propiciaría un espacio de desenvuelta deliberación. Una afirmación así nos aboca de lleno al tipo de sociedad resultante de la racionalidad comunicativa teorizada por Habermas. Pero sería precipitado lanzarnos a afirmar semejante consideración sin haber establecido previamente un significado preciso de la acción social que en la plaza tiene lugar. Así pues, las siguientes indagaciones pretenden contrastar la hipótesis según la cual las formas de relación interpersonal en Sol podrían considerarse una concreción positiva de la teoría normativa de la acción comunicativa.

\section{RACIONALIDAD COMUNICATIVA}

En Plaça del Sol la aparente diversidad de matices de los individuos resulta neutralizada dentro de un marco de aceptable convivencia mediada por una praxis comunicativa integral. El respeto mutuo se distribuye por igual sin importar aspectos raciales o nacionales, de género ni de clase. Nos encontramos, a fin de cuentas, ante la representación colectiva de un espacio supuestamente autoorganizado y asambleario, donde se producen las condiciones ideales para una racionalidad 
comunicativa que propicie el surgimiento de "una situación ideal del habla especialmente inmunizada contra la represión y la desigualdad" (Habermas, 1999a: 48).

Aunque las creencias ideologías o religiosas de los participantes sean distintas, así como su procedencia nacional o extracción socioeconómica, al estar sentados sobre el pavimento de forma indistinta e indiscriminada, se encontrarían mancomunados en un ensueño de auténtica igualdad: los individuos de Plaça del Sol expresarían una vida social policromática, un crisol de identidades diversas, un caleidoscopio multicultural a fin de cuentas, atravesado por una supuesta hermandad ecuménica que unificaría las diferencias aparentes. Y el mecanismo que haría posible suspender las desigualdades a fin de alcanzar el mutuo entendimiento no sería otro que la palabra. Ahora bien, ¿sería Habermas ingenuamente optimista al visualizar la plaza como un espacio de «racionalidad comunicativa»? Para el pensador alemán, el lenguaje es un vehículo de comunicación que, al ofrecer argumentarios susceptibles de crítica, contribuye a los procesos de racionalización humana. Por consiguiente, las expresiones lingüísticas no harían sino favorecer las posibilidades de racionalidad (Lessnoff, 2014: 298).

Sin embargo, las entrevistas efectuadas han permitido constatar que parte considerable de la comunicación lingüística entre los individuos presentes en Plaça del Sol se dedica al esfuerzo de presentarse de una manera determinada, por lo que, en no pocas ocasiones, la acción comunicativa se convierte en dialogue de sourds. a un número considerado de entrevistados no les duele prendas reconocer que la mayor parte del tiempo de las intervenciones de cada cual en la conversación es ocupado en hablar de uno mismo y de sus problemas, por lo que no le otorgan demasiada consideración a los planteamientos de sus interlocutores ${ }^{7}$. Siendo así diríamos que, para los participantes, la esfera social comprendida en sus encuentros adquiere significación en tanto en cuanto es asimilada como un escaparate en el que exhibirse.

Dicho lo cual no podemos pasar por alto que la anterior consideración remite a la "acción dramatúrgica» según la cual, "una interacción social [se percibe] como un encuentro en que los participantes constituyen los unos para los otros un público visible y se representan mutuamente algo" (Habermas, 1999a: 131). Ahora bien, puesto que esta será una cuestión sobre la cual volveremos a referirnos más adelante, por ahora no queremos apartarnos del interrogante por el cual nos cuestionábamos la racionalidad comunicativa presente en la plaza.

A tenor del estudio realizado, podemos constatar que muchas de las conversaciones no tienen otro propósito que el mutuo reconocimiento de los individuos implicados: la ligereza e inconstancia de los asuntos conversados revela que la denominada fática o relacional es la principal función del lenguaje en Plaça

\footnotetext{
${ }^{7}$ Que la comunicación oral, antes que conversación, deviene un soliloquio tras otro, una superposición de solipsismos monologados, se desprende de las palabras de una joven que afirma: "a ver, nostras venimos aquí a contarnos nuestras cosas, las de cada una; que si un chico me dijo de quedar, o lo que sea, y lo que nos digan... pues a ver, somos amigas, nos escuchamos, pero lo que quiere una es contar lo suyo".
} 
del Sol. Se trata de una función lingüística en la que el mantenimiento de la apertura del canal comunicativo es de mayor importancia que el mensaje que pueda discurrir por susodicho canal. Sin embargo, ello no niega la racionalidad comunicativa en las dinámicas de interacción que operan en la plaza: siguiendo los razonamientos habermasianos diríamos que, si la expresión de los interlocutores descansa sobre una creencia que es verdadera, independientemente de lo relevante o fútil que ésta sea, la acción comunicativa es racional.

De este modo, decir que "en la gelateria Giolitti de Roma se encuentran los helados más ricos que he probado" ${ }^{8}$ bien es una afirmación racional, que además compromete a su emisor con la racionalidad, por cuanto que éste, el emisor, debe argumentar sus creencias o, en el caso que sea pertinente, modificarlas. En cualquier caso, a fin de que su mensaje asuma validez, e independientemente de las evidencias que presente, debe ser concebido como verosímil por parte de sus interlocutores. De ahí que Habermas (1999a: 24) afirme que "la estrecha relación que existe entre saber y racionalidad permite sospechar que la racionalidad de una emisión o de una manifestación depende de la fiabilidad del saber que encarnan". En otras palabras, existe racionalidad comunicativa siempre que la veracidad de la conversación pueda ser cuestionada y contrastada.

\section{ACCIÓN REGULADA POR NORMAS}

De igual manera, para Habermas una acción es racional cuando es coherente con un determinado contexto normativo que, aun siendo criticable, es asumido como legítimo (Lessnoff, 2014: 299). Razón por la cual los presentes en Plaça del Sol se estarían comportando de manera racional en la medida que no ocasionan alboroto, no tiran las mesas de cafeterías cercanas al suelo ni orinan en plena calle, y, por último, desalojan la plaza cuando, a partir de una cierta hora de la noche, la policía se lo pide.

Ello nos exige tratar aquello que Habermas (1999a: 123) menciona como «acción regulada por normas» para referirse a la acción que expresa "el cumplimiento de una expectativa generalizada de comportamiento". Efectivamente, observamos que la acción discurre por un contexto normativo que regula las interacciones sociales que se llevan a cabo en la plaza cuando advertimos que el libre acceso al espacio público no supone un deslizamiento de las actividades dialógico-comunicativas que mayormente se llevan a cabo hacia otro tipo de actividades que comportan la cohesión de los cuerpos en pos de una acción común incompatible con el orden social establecido.

Por tal motivo es que, si bien en un primer momento la mayoría de entrevistados se arroga para sí la posibilidad de realizar en la plaza aquello que sea que se encuentre dentro de sus apetencias, al preguntarles si, además de conversar y consumir un refrigerio, sería posible -por ejemplo- disputar un partido de fútbol, entonces únicamente una pequeña parte de los mismos reconoce la capacidad efectiva de desarrollar semejante actividad. A más decir, se evidencia

\footnotetext{
${ }^{8}$ El ejemplo está tomado de una conversación en la que una mujer le relataba a su amiga su viaje a Italia.
} 
completamente la idealización de la apropiación espontánea del espacio público cuando a los entrevistados se les pregunta si creen que podrían levantarse barricadas en la plaza9. En ese momento parece evidenciarse que "el sentido del mundo social puede aclararse por referencia a la vigencia de normas" (Habermas, 1999a: 128) que dictan las formas de ocupar y actuar en el espacio público.

Pero el sentimiento de pertenencia mutua a una misma situación, por parte de los distintos grupos de personas que hacen de la Plaça del Sol un espacio lúdicorecreacional de encuentro, conversación y refrigerio, no resulta únicamente de compartir un marco normativo. En adelante nos interrogaremos al respecto de la formación semiótica de la esfera social de la plaza a partir de la actuación subjetiva que llevan a cabo sus usuarios.

\section{ACCIÓN DRAMATÚRGICA}

Apoyándose en el interaccionismo simbólico de Erving Goffman, Habermas considera que la acción dramatúrgica es aquella en que los individuos -concebidos ahora como actores- llevan a cabo un determinado rol durante la interacción social. Consiguientemente, el actor es aquel que "se relaciona con su propio ámbito subjetivo" por cuanto que debe "presentar ante los demás un determinado lado de sí mismo" (Habermas, 1999a: 132). Dicho lo cual, si lo que se quiere es dar cuenta de las actuaciones escénicas dramatizadas en Plaça del Sol, resulta cuanto menos elocuente la afirmación de un sujeto que afirma lo siguiente: "venimos a lo que venimos, a muchas cosas, y sí que venimos a mostrarnos, a que nos vean (...) pues claro que nos gusta mostrar la imagen que queremos dar, y estar aquí nos sirve para eso, pero yo no pienso que vengo a eso cuando vengo".

Ciertamente, no son pocos aquellos actuantes que al ser preguntados por su exposición admiten, aunque de manera vacilante y con reservas, el juego de máscaras que se produce en el espacio en que se congregan los presentes; pero ninguno considera que la representación de una suerte de coreografía colectiva es en sí misma el principal elemento por el cual participar de la situación proyectada en la plaza. Así es que la mayor parte de los actuantes entrevistados asume que su presencia en Sol desprende una determinada impresión, aunque únicamente una pequeña parte de los mismos reconoce que la impresión que fomenta sea deliberada, y ninguno de ellos considera que la voluntad por ofrecer una impresión particular, de ser parte de la elaboración de un determinado cuadro escénico, sea la razón definitiva por la cual participar en la representación que acoge la plaza.

Por otro lado, la actuación deliberada, a la que bruscamente podríamos considerar como engañosa, no necesariamente es aquella que procede del placer oculto que se haya en la ganancia privada, pues no son pocas las ocasiones en que

\footnotetext{
${ }^{9}$ Después de que afirmase "hacemos lo que queremos: la plaza es nuestra, ¿no lo ves?", un usuario acabó reconociendo por iniciativa propia que las actividades que en Plaça del Sol pueden ser realizadas se encuentran fuertemente limitadas por la ordenanza municipal de civisimo. Si quiera esa misma actividad que realizaban en ese momento -conversar apaciblemente y beber- podía ser sostenida a partir de cierto momento: "en un par de horas vendrán los [policías] de la local y nos echarán".
} 
un individuo actúa de forma artificiosa solamente por mantener aquellas apariencias que le permitan adecuarse al sistema de creencias y apariencias del colectivo humano en que se encuentra. En tal caso, el bien común prevalecería como sustrato de la íntima certeza de una simulación que, por ello, no debe siempre entenderse como espuria o éticamente reprobable. Un botón de muestra lo ofrece la siguiente afirmación: "aunque me parezca un poco gilipollada esto de estar aquí sentado, lo hago porque mis amigos suelen venir aquí, y mira, me vengo (...) no se trata de que haya discordia". Advertimos, por ello, que el escepticismo que puede generar la actuación en la que uno mismo participa se ve compensado por la seguridad que ofrece la inserción del individuo en la coreografía colectiva que se dramatiza en la plaza.

Conforme a lo anterior, no resulta un detalle menor que, al ser preguntados por aquello que sería el espíritu constitutivo o el carácter distintivo de Plaça del Sol, lo que Ilamaríamos el ethos del lugar, las respuestas en mayor medida recurrentes sean "buen rollo" y "buenrollismo"10. En virtud de lo cual sería un descuido no advertir que la percepción de los actuantes al respecto de la sustancia de la situación social de la que forman parte resultaría próxima a la lógica dominante del capitalismo según algunos de aquellos autores que han estudiado su expresión contemporánea. Por motivos obvios resultaría imposible referenciar la literatura existente acerca del sentir cultural de nuestra época (Zeitgeist), por lo que nos sirve de punto de apoyo citar a Slavoj Zizek (2011: 67) cuando afirma que "el nuevo espíritu del capitalismo recuperó triunfalmente la retórica igualitaria y antijerárquica de 1968, presentándose a sí mismo como una victoriosa rebelión libertaria". Una vez introducida ya la cuestión del «sistema» (capitalismo), resulta pertinente referirse a la instrumentalidad que lo posibilita por medio de una acción estratégica.

\section{ACCIÓN ESTRATÉGICA}

Habermas denomina «acción estratégica» a aquella en que los individuos actúan, involucrando a otros agentes, en función de "la realización de un propósito, dirigida por máximas y apoyada en una interpretación de la situación" (Habermas, 1999a: 122). Al respecto de lo cual será cuestión de señalar que, detrás de una amalgama de prácticas uniformes (la conversación circunspecta y la bebida mesurada), en Plaça del Sol aparece la movilización subrepticia de cierta aspiración de proyección individual por medio de la exposición de símbolos que, mostrados ambigua u oblicuamente, ocultan su verdadero propósito ${ }^{11}$. Por consiguiente, si bien la (ficción

${ }^{10}$ Este último término - buenrollismo- supone la sustantivación de una expresión coloquial buen rollo-, que alude a un comportamiento o actitud amigable y desenfadada. Consiguientemente, el "buenrollismo" manifiesta una predisposición amistosa donde no tienen cabida los conflictos ni las discusiones. La mayor parte de las otras respuestas pronunciadas se sitúan en la misma línea semántica: "amistad", "encuentro", "libertad", "fresca". Un último grupo de respuestas alude a la ubicación del lugar y/o a sus atributos simbólicos: "Gràcia", "vida mediterránea", "Barcelona".

${ }^{11}$ Símbolos de un status elevado que son indirectamente exhibidos, como los iPhones o las referencias a viajes a Mykonos, Berlín o Nueva York. Nos encontraríamos, por tanto, ante unas preferencias manifestadas, a las que Pierre Bourdieu (1998: 53) denomina "gustos», que 
de) horizontalidad suspende la estratificación social, lo cierto es que ello no comporta la desaparición de una acción fundamentada en el cálculo de medios para la obtención de aquellos fines orientados a la promoción del status personal.

No obstante, si la interacción social de Plaça del Sol tiene éxito como forma ilusoria de espontánea congregación y horizontal comunicación se debe a que logra escenificar una situación donde se encubre la intención de los individuos por orientar sus acciones hacia la búsqueda del reconocimiento de los demás y de la distinción sobre los otros. De resultas a lo cual, es pertinente recordar a Habermas (1999a: 126-127) cuando afirma que, en la maniobra estratégica, "el resultado de la acción depende también de otros actores, cada uno de los cuales se orienta a la consecución de su propio éxito, y sólo se comporta cooperativamente en la medida en que ello encaja en su cálculo egocéntrico de utilidades".

Así que, antes de encontrarnos en un universo postcapitalista donde la armoniosa socialización entre individuos no requiere más que una sincera y frugal interacción, nos hallamos ante una oculta competición en la que los individuos se someten al constante esfuerzo de la exigencia que supone "incorporarse y ejemplificar los valores oficialmente acreditados de la sociedad" (Goffman, 2012: 50). A la postre, la suspensión de la jerarquía social no supone más que abrir un espacio aparentemente neutro donde recrear una nueva estratificación por medio de la teatralización social que opera en la plaza ${ }^{12}$.

Nos encontramos, pues, en un ámbito escénico que levanta la pesada ancla que inmoviliza las posiciones sociales a fin de permitir un reordenamiento de dichas posiciones según criterios estéticos que operan en el plano simbólico. Y es en esta posibilidad de proyectar una nueva identidad en el trasmundo de la plaza que los participantes inconscientemente reproducen las aspiraciones de ascenso social existentes allende la misma plaza.

Necesario será tener en cuenta la paradoja resultante. Por un lado, los elementos indicativos de status que son susceptibles de generar competitividad serían implícitamente proscritos por interferir en la recreación utópica de la plaza como espacio público de libertad e igualdad, mientras que, por otro lado, su presencia no deja de ser sugerida, rápidamente evocada o indirectamente revelada: unas gafas de sol marca Ray-Ban, valoradas en más de cien euros, que acompañan unas alpargatas de tela con suela de goma, o un vestido de figura harapienta que oculta la etiqueta en que aparece la firma de la casa diseñadora, son ejemplos que, a modo de signos

resultan sintomáticas del capital económico y cultural que poseen determinados grupos sociales.

12 Por «teatralización social» nos referimos a la actuación de cierta subcultura contemporánea de ademanes cosmopolitas y sensibilidad progresista que, bien mirado, podría resultar una adecuación popularizada de aquellos grupos sociales que en la segunda mitad del pasado siglo fueron denominados bobo (bourgeois-bohème) o gauche caviar. De hecho, si para aludir la idiosincrasia preponderante de los actuantes en la plaza debiéramos recurrir a la taxonomía de las tribus urbanas, probablemente aquella referida fuese la denominada hipster, en la que los estilos de vida aparentemente alternativos se relacionan con preferencias de consumo sofisticadas a las que tienen acceso estratos sociales que disponen de un significativo poder adquisitivo. 
Barcelona ante la mirada habermasiana. Primeros materiales para una sociología de la acción comunicativa

delatores, ponen de manifiesto el sesgo expresivo por el cual, al cancelar las categorías socioeconómicas del mundo real, las expresiones suntuosas deben asumir una espuria apariencia negligente y descuidada ${ }^{13}$.

Se podría pensar que alardear explícitamente de status podría interpretarse como un signo demasiado apegado a las estratificaciones de clase convencionales, lo que indicaría la poca predisposición del sujeto por involucrarse a ese dominio relativamente autónomo, parcialmente liberado de las responsabilidades y obligaciones (así como de las asimetrías) de la sociedad realmente existente, que es la plaza. En consecuencia, el actor en cuestión podría suscitar suspicacia o recelo, o por lo menos extrañeza, en tanto en cuanto no cumpliría con ese requisito, implícitamente necesario para participar de la esfera social de la plaza, que es el ocultamiento de las pretensiones de distinción social.

Pero si es posible obtener una explicación estructural de los resultados de esta investigación según los esquemas de pensamiento habermasiano, entonces debemos regresar a la noción de "opinión pública» que presentábamos anteriormente. No podemos olvidar que ésta surgía como un espacio de discusión en el cual los interlocutores, en situación de reciproca libertad, se sirven de su juicio crítico para cuestionar la autoridad política. No obstante -y aquí tropezaríamos con el gran impedimento para que la razón comunicativa pudiera avanzar- nos encontramos con que la «opinión pública» tiende a desvincularse de sus facultades críticas. De tal manera que "su relación con la dominación, con el poder, aumenta, por así decirlo, a espaldas suyas: los deseos «privados» de automóviles y refrigeradores caen bajo la categoría de "opinión pública»" (Habermas, 1981: 268). Dicho esto se entenderá que el examen de Plaça del Sol contribuiría a corroborar que "el espacio de la opinión pública y el ámbito de lo público (Öffentlichkeit) hoy están intervenidos por intereses sectoriales, mediáticos y políticos que impiden la plasmación de esta situación ideal comunicativa" (Giner, 2017: 768).

\section{CONCLUSIONES}

Aparte de 1) la «racionalidad comunicativa» como tipo ideal de la «acción comunicativa», en las páginas precedentes hemos visto que «las manifestaciones comunicativas» de la plaza se expresan por medio de 2) la «acción regulada por normas», por la cual el sujeto entabla una relación con el mundo social legítimamente regulado, 3) la "acción dramatúrgica», por la cual el sujeto entabla una relación con las vivencias subjetivas, y 4) la "acción estratégica», por la cual el sujeto entabla una relación con finalidades propias del mundo objetivo. Ante lo cual, no podemos soslayar que "las manifestaciones comunicativas están insertas a un mismo tiempo en diversas relaciones con el mundo" (Habermas, 1999b: 171). De

\footnotetext{
13 "Aquí hay mucho pijo de cuna, pero que no lo aparentan", afirma una mujer entrevistada. En este punto se columbra el empeño, por parte de los actuantes en Plaça del Sol, de seguir comportamientos y realizar expresiones que, sin llegar a generar un desclasamiento con respecto a las condiciones objetivas que permiten su situación en el mundo, difuminan su posición social. El propósito de ello - deliberado o, más bien, irreflexivo- no sería difícil de imaginar: desbordar un espacio de prácticas sociales específico y, de este modo, manifestar sus opciones de incidir/influir sobre el conjunto de la estructura social.
} 
modo que, aunque no todas esas relaciones estén caracterizadas por la pureza de la «racionalidad comunicativa», sí se complementan como parte de una urdimbre comunicativa que propicia el entendimiento (Verständigung) de los interlocutores. En este sentido es que el «mundo de la vida» supone el trasfondo a partir del cual se producen las relaciones de los distintos modos de comunicación orientados al «Verständigung».

Ahora bien, la cuestión se complica cuando la «acción estratégica» adquiere primacía dentro de los modos de comunicación presentes en la plaza. En ese entonces, cuando "las actitudes de los actores sociales con respecto a los otros actores sociales son fundamentalmente más estratégicas que comunicativas" (Lessnoff, 2014: 308), se podría decir que "los mecanismos del sistema se desligan cada vez más de las estructuras sociales a través de las cuales se cumple la integración social" (Habermas, 1999b: 217). De manera que, en última instancia, el «mundo de la vida» corre el riesgo de disiparse en la abrumadora lógica del «sistema». Por ello comenzamos a intuir las implicaciones que posee para el «mundo de la vida» la «acción estratégica» observada en Plaça del Sol: aunque a simple vista la conversación aparentemente distendida y desenfadada adquiere absoluta preponderancia con respecto a comportamientos delicados o conflictivos, lo cual sugeriría que la interacción social que se desarrolla en la plaza resulta concomitante con la racionalidad comunicativa del «mundo de la vida», no escapa a nuestra mirada que de manera subyacente opera una "acción estratégica encubierta» que tiene por motivación la obtención de la distinción de status personal dentro del entramado social que se representa en la plaza.

En resumidas cuentas acabaremos por concluir que, a poco que seamos perspicaces durante el estudio realizado, observamos que la acción e interacción de los individuos en Plaça del Sol resulta porosa a una «racionalidad instrumental» estimulada por un sistema productivo flexible y reticularmente organizado: las dinámicas de interacción social mediadas por la comunicación que se llevan a cabo en Plaça del Sol propician una experiencia portadora de las prácticas posfordistas de organización social a escala reducida, a saber, una retícula de grupos aparentemente autónomos que, mediante flujos comunicacionales, cooperan entre sí de manera flexible y descentralizada para satisfacer un amplio espectro de demandas simbólicas vinculadas al consumo cultural de un estilo de vida particular. Ante lo cual podríamos afirmar que, en cierta forma, la dinámica social de Plaça del Sol podría concebirse como la miniaturización de la estructura social de acumulación basada en los flujos informacionales de la sociedad-red.

Aunque ésta sea una conclusión sombría, que viene a confirmar la colonización de la «sociedad» por parte del "sistema», nos sentimos tentados a decir que el espacio público de Plaça del Sol aparece como una esfera aséptica de conversación inocua que permite la inclusión de cualquier individuo a la representación de una dramaturgia pospolítica donde se escenifican, carentes de cualquier contenido material, los mixtificados principios de libertad e igualdad. Al tiempo que los asuntos controvertidos no son sometidos a debate democrático, los modos de comunicación presentes en la plaza tienden a ser autorreferenciales por cuanto que se orientan a la promoción simbólica de un status singular. Dicho ahora con mayor rotundidad, si 
para Habermas la racionalidad comunicativa remite a la capacidad potencial de los individuos por generar acuerdos o consensos, lo cual es en sí mismo una forma de acceso a un conocimiento emancipatorio, en el espacio público examinado nos encontramos con que la fetichización de los estilos de vida subsumidos a la lógica del consumo impide la separación del sujeto con el mundo de los objetos.

Según sostiene Habermas, la comunicación es el elemento capaz de superar la instrumentalización de la razón; pero para que ello ocurra la comunicación debe previamente emanciparse del ámbito de la dominación. Al no cumplirse este requisito se comprende que, si bien en un primer momento intuíamos advertir en la espesura comunicativa que caracteriza Plaça del Sol un espacio público que pudiera dar lugar a una situación libre de enajenación instrumental, una atenta observación de los procesos comunicativos contribuye a disipar cualquier optimismo que pudiera albergar semejante posibilidad. De manera que, invocando el diagnóstico que realiza el propio Habermas (1993: 452), "la razón centrada en el sujeto queda, pues, disuelta por la racionalidad sistémica". En consonancia con la incapacidad de hallar un mundo en común trenzado a partir de relaciones de reciprocidad que doten de densidad humana a la comunidad política, podría decirse que los ciudadanos que encontramos en Plaça del Sol responden al arquetipo de idiotes, esto es, el término con el que en la Antigua Grecia se denominaban a quienes únicamente se preocupan de sus asuntos privados y particulares.

\section{EXCURSO: OPINIÓN PÚBLICA Y CIUDADANÍA ACTIVA}

Directamente vinculado con lo anterior, ya sólo podríamos añadir que la acción comunicativa en Plaça del Sol resulta claramente insuficiente para el propósito de articular un compromiso cívico que pueda dar lugar a una acción política orientada hacia objetivos que, trascendiendo el ámbito privado de los individuos, se proyecten sobre la res publica. Razón por la cual, puesto que en un primer momento caracterizábamos Plaça del Sol refiriéndonos al ideal de ciudadanía activa reivindicado por Hannah Arendt, después de expresar las conclusiones obtenidas tras la investigación realizada sería conveniente aludir nuevamente a esta destacada autora. Arendt sería una pensadora difícil de catalogar si no fuese por su inequívoca apuesta por un republicanismo cívico y, como corolario de ello, por su concepción de la actividad pública como un fin en sí misma.

A su entender, la opinión pública únicamente puede formarse después de considerar distintas perspectivas al respecto de un asunto, pues "cuantos más puntos de vista diversos tenga yo presentes cuando estoy valorando determinado asunto (...) tanto más fuerte será mi capacidad de pensamiento representativo y más válidas mis conclusiones, mi opinión". Pero ello comporta, nos dice la filósofa alemana, que el proceso de formación de la opinión pública debe encontrarse caracterizado por el "desinterés", lo que significa "estar libre de los propios intereses privados" (Arendt, 1996: 254). Solo cuando existe un espacio público en que se dan esas condiciones, las que proceden de prácticas compartidas que den lugar a un mundo en común, es posible la emergencia de una opinión pública diáfana; en cuyo caso no queda sino resolver que tampoco para Arendt encontraríamos en el espacio público de Plaça del 
Sol -donde el narcisismo disimulado de cada cual asume primacía con respecto a la creación de un espacio de compromiso compartido- atisbos de su conformación.

Una descripción del espacio público como la precedente se vincularía directamente con los planteamientos de Manuel Delgado. Ciertamente, la alusión a este antropólogo resultaría oportuna tan pronto como se advierte la semblanza de su noción de espacio público con la significación que, a partir del análisis de las maneras de actuar e interactuar de los individuos, asume la plaza: el escenario comunicacional de Plaça del Sol, en el cual los individuos se distribuyen espontáneamente sobre el pavimento articulando una suerte de opinión pública improvisada, sería así la ubicación palpable de "la experiencia de una imaginaria fraternidad universal" (Delgado, 2015: 42), esto es, un espacio de aparente entendimiento en el cual los elementos friccionales son solapados por medio de valores afirmados con amplia grandilocuencia. Asistiríamos, por tanto, a la concreción palpable de aquello que, según Delgado (2015), expresa la ideología que impregna el concepto de espacio público: una arcadia de civilidad en la cual los individuos se sienten como parte de una confraternidad interclasista de ciudadanos supuestamente libres e iguales.

Por decirlo con mayor exactitud, en Manuel Delgado "la noción de espacio público remite a un proscenio amable y desconflictivizado" donde se materializa "la versión expandida y universal de la esfera pública burguesa y de su despliegue como sociedad civil" (2016: 27-28). Conforme a lo cual, la opinión del público -cuyo desarrollo teórico Delgado atribuye a la labor que autores como Habermas y Arendt efectúan a partir de la idea de sociedad civil previamente conceptualizada por Hegel- se caracterizaría por ser un "conjunto disciplinado y responsable de individualidades" (2015: 46) cuya función contemporánea seria humanizar el capitalismo (el "sistema», según diría Habermas) y, de este modo, desactivar una crítica sustantiva al mismo. La expresión política que actualmente asumiría la opinión pública sería el ciudadanismo: Delgado entiende por ciudadanismo un modo de vida que, realizando empíricamente el proyecto de una modernidad que para Habermas se mostraba inconclusa, aspira a reformar éticamente el capitalismo por medio de la reivindicación abstracta de valores democráticos (2015: 31-32) ${ }^{14}$.

Sin embargo, en ningún caso cabe esperar que Habermas se reconociese en la crítica que Manuel Delgado realiza sobre sus postulados filosófico-políticos. Esto es así por cuanto que su teoría de la acción comunicativa no comporta -a diferencia de lo que podría haberse presupuesto al momento inicial de trasladar su sistema normativo al cosmos social de Plaça del Sol- la cancelación de los antagonismos sociales constitutivos de la sociedad capitalista ni la disolución de los contenciosos políticos consustanciales a cualquier formación social. De hecho, una mirada atenta a su obra nos llevaría a advertir, como sostienen algunos autores, que "para Habermas, la sociedad civil opera como una instancia esencialmente negativa, productora de antagonismos políticos, que son elementos indispensables para la

14 Por consiguiente, el «ciudadanismo» no tendría ninguna relación con la fuerza políticamente disruptiva de la ciudadanía que protagonizó las revoluciones de finales de los siglos XVII y XIX. 
Barcelona ante la mirada habermasiana. Primeros materiales para una sociología de la acción comunicativa

existencia de una sociedad democrática" (Castro-Gómez, 2015: 391). Ciertamente, la sociedad civil, pensada como el conjunto heterogéneo de agrupaciones ciudadanas surgidas del «mundo de la vida», sería la esfera a partir de la cual podría efectuarse la crítica a ( $y$, de este modo, antagonizar con) la racionalidad económica y al (el) burocratismo político del «sistema» (Habermas, 1998).

Por lo que respecta a Arendt, es el interés público, que no debiera entenderse como la suma de los intereses privados -la mayor parte de los cuales son apolíticos-, aquello que dota de sentido el mundo común (Passerin d'Entrèves, 2012: 198). Cierto es que el mundo común no está únicamente conformado por consensos, pues la conformación de una opinión pública no deja de ser un proceso problemático en el que, en muchos casos, prevalecen las disputas y los conflictos. Pero lo relevante es que las opiniones enfrentadas lo están con respecto a una dimensión política de los asuntos públicos que se encuentra ausente en la autorreferencialidad de las cuestiones particulares que son abordadas por los individuos que concurren en el espacio público de Plaça del Sol. De consuno con el pensamiento de Arendt podría decirse que, al tiempo que la participación en los asuntos de la comunidad proporciona la experiencia de la libertad, la reclusión en las cuestiones privadas puede entenderse como la consecuencia de una ciudadanía desprovista de una verdadera vita activa propia de ciudadanos libres y responsables.

En vista de ello, el ejercicio de los derechos de reunión y expresión que se efectúan en el espacio público de Sol, así como la aparente -aunque equívocadisposición de los asistentes a la plaza para resolver cuestiones por medio del debate y la deliberación, no serían por sí mismos elementos suficientes para hallar la ciudadanía republicana a la que, cada cual con sus distintos matices, apelan estos autores. No sólo es que el modelo de ciudadanía que asumen Habermas (1997) y Arendt (2015) desincentive actitudes pasivas con respecto a la comunidad política (como aquellas que se manifiestan en Plaça del Sol), sino que además admite la desobediencia civil como recurso por el cual resituar la sociedad civil como principio rector de la organización de la comunidad política. Por consiguiente, la noción de ciudadano por la que apuestan estos autores se encontraría considerablemente alejada de ese sujeto colectivo ensimismado que asiste a Plaça del Sol como protagonista de las representaciones de una sociedad estructuralmente pacificada que ahí se interpretan.

\section{BIBLIOGRAFÍA}

ARATO, Andrew y COHEN Jean. (1999). "La sociedad civil y la teoría social", en OLVERA, Alberto. La sociedad civil. De la teoría a la realidad. México, D.F.: El Colegio de México.

ARENDT, Hannah. (1996). Entre el pasado y el futuro. Ocho ejercicios sobre la reflexión política. Barcelona: Península. 
ARENDT, Hannah. (2015). "Desobediencia civil", en Crisis de la república. Madrid: Trotta.

BOURDIEU, Pierre. (1998). La distinción. Criterios y bases sociales del gusto. Madrid: Taurus.

DELGADO, Manuel. (2015). El espacio público como ideología. Madrid: La Catarata.

DELGADO, Manuel. (2016). Ciudadanismo. La reforma ética y estética del capitalismo. Madrid: La Catarata.

DOMÈNECH, Antoni (1981). "Prólogo a la edición castellana: El diagnóstico de Jürgen Habermas, veinte años después", en HABERMAS, Jürgen. Historia y crítica de la opinión pública. La transformación estructural de la vida pública. Barcelona: Gustavo Gilli.

CASTRO-GÓMEZ, Santiago. (2015). Revoluciones sin sujeto. Slavoj Zizek y la crítica del historicismo posmoderno. México D.F.: Akal.

GARCÉS, Marina. (2015). "Racionalización y emancipación. La respuesta de Jürgen Habermas", en Filosofía inacabada. Barcelona: Galaxia Gutenberg.

GINER, Salvador. (2017). "Los pensadores contemporáneos de la condición moderna", en Historia del pensamiento social. Barcelona: Ariel.

GOFFMAN, Erving. (2012). La representación de la persona en la vida cotidiana. Buenos Aires: Amorrortu Editores.

HABERMAS, Jürgen. (1981). Historia y crítica de la opinión pública. La transformación estructural de la vida pública. Barcelona: Gustavo Gili.

HABERMAS, Jürgen. (1993). El discurso filosófico de la modernidad. Madrid: Taurus.

HABERMAS, Jürgen. (1997). "La desobediencia civil, piedra de toque del estado democrático de Derecho", en Ensayos políticos. Barcelona: Península.

HABERMAS, Jürgen. (1998). "Sobre el papel de la sociedad civil y de la opinión pública", en Facticidad y validez: sobre el derecho y el estado democrático de derecho en términos de teoría de discurso. Madrid: Trotta. 
HABERMAS, Jürgen. (1999a). Teoría de la acción comunicativa l. Racionalidad de la acción y racionalización social. Madrid: Taurus.

HABERMAS, Jürgen. (1999b). Teoría de la acción comunicativa Il. Crítica de la razón funcionalista. Madrid: Taurus.

HABERMAS, Jürgen. (2008). "La modernidad, un proyecto incompleto", en FOSTER, Hal (ed.). La posmodernidad. Barcelona: Kairós.

LESSNOFF, Michael H. (2014). "Jürgen Habermas: ética del discurso y democracia", en La filosofía política del siglo XX. Madrid: Akal.

PASSERIN D'ENTRÈVES, Maurizio. (2012). "Hannah Arendt y la idea de ciudadanía", en MOUFFE, Chantal (ed.). Dimensiones de democracia radical. Pluralismo, ciudadanía, comunidad. Buenos Aires: Prometeo libros.

PEÑA, Javier. (2000). La ciudadanía hoy: problemas y propuestas. Valladolid: Universidad de Valladolid. Secretariado de Publicaciones e Intercambio Editorial.

RODRÍGUEZ IBÁÑEZ, José Enrique. (2011). "La crítica de la modernidad", en GINER, Salvador (coord.). Teoría sociológica moderna. Barcelona: Ariel

ZIZEK, Slavoj. (2011). Primero como tragedia, después como farsa. Madrid: Akal 